\title{
Intracardiac metastasis of squamous cell carcinoma of the penis
}

\author{
Sheila Aparecida Coelho Siqueiraa, Camila Satie Tomikawa ${ }^{a}$
}

Siqueira SAC, Tomikawa CS. Intracardiac metastasis of squamous cell carcinoma of the penis. Autopsy Case Rep [Internet]. 2013; 3(4): 23-8. http://dx.doi.org/10.4322/acr.2013.035

\section{ABSTRACT}

\begin{abstract}
Penile cancer shows variable incidence in different countries with a higher prevalence in developing countries. Squamous cell carcinoma represents the most common histologic type. The seventh decade of life corresponds to the mean age at diagnosis, but it is not an unusual diagnosis among young adults. Most cases present as "in situ" neoplasia or loco regional disease; however, systemic disseminated disease occurs via lymphatic and/or hematogeneous routes. The lymph nodes, liver, and lungs are the most frequently involved sites whereas the heart constitutes an exceptional and atypical site for penile cancer metastases. We report a case of a 79-year-old patient who presented a metastatic squamous cell carcinoma of the penis with intracardiac dissemination. The patient had a past history of cardiomyopathy, which required an artificial cardiac pacemaker implantation. He had been treated 1 year before with a partial penectomy but was admitted for emasculation due to the cancer relapse. During the postoperative period, he experienced sudden respiratory distress and died. The autopsy findings showed metastatic disease into the cardiac right chambers, pulmonary tumoral thrombi, and pulmonary hilar involvement. The authors call attention to the possibility of the presence of pacing leads, cardiomyopathy and the altered low blood flow in the right chambers, as predisposing factors for the tumoral seeding in this case.
\end{abstract}

Keywords: Autopsy; Penile Neoplasms; Neoplasm Metastasis.

\section{CASE REPORT}

A 79-year-old male patient sought medical attention because of the relapse of a lesion in the penile stub. One year earlier, he had been treated with partial penile amputation for squamous cell carcinoma. His past medical history included hypertension and a third-degree atrioventricular block, which required the implantation of an artificial cardiac pacemaker. He was admitted and submitted to emasculation and regional lymphadenectomy. Pathological examination of the surgical specimen revealed invasive squamous carcinoma with regional lymph-node involvement.

Two days after the surgery the patient presented hypotension and marked leukocytosis, but apparently, with no evidence of infection. However, antibiotics and vasoactive drugs were added to the therapeutic regimen in an attempt to achieve hemodynamic stabilization. Doppler

\footnotetext{
a Department of Pathology - Hospital das Clínicas - Faculdade de Medicina - Universidade de São Paulo, São Paulo/SP - Brazil.
} 
echocardiography revealed diffuse left ventricle hypokinesia; mitral and tricuspid valves insufficiency, and the presence of the pacemaker's electrode located in the right ventricle. Eight days after surgery the patient experienced sudden respiratory discomfort and died soon after.

\section{AUTOPSY FINDINGS}

On external examination, the anthropometric measures revealed the body of a man $163 \mathrm{~cm}$ in height with a weight of $69 \mathrm{~kg}$. A recent surgical scar measuring $6.5 \mathrm{~cm}$ replaced original topography of the external genitalia.

At the opening of the thoracic cavity a small amount of pleural effusion was present bilaterally, and a thick pericardium had adhered to the pleura. The heart was enlarged and weighted $530 \mathrm{~g}$ (reference mean value [RMV]: $327 \mathrm{~g}$ ). On sectioning the right chambers, a whitish tumoral structure loosely adhered to the endocardium (Figure 1) was found involving the atrium and the ventricle trespassing the tricuspid valve and covered the pacemaker electrodes.

The gross appearance of these structures resembled infectious endocarditis. After microscopic examination, it was clear that the cardiac involvement was represented by neoplastic tissue. On the left ventricle, the papillary muscles were hypertrophied. Histological examination showed myocardial sclerosis and an unspecific inflammatory infiltrate of lymphocytes and eosinophils permeating the myocardiocytes. The tumoral mass was attached to the endocardium with focal invasion. On microscopy, marked necrosis was present, but preserved areas of squamous cell carcinoma were evident (Figure 2A and $2 \mathrm{~B}$ ).

The right and left lungs weighed $660 \mathrm{~g}$ and $510 \mathrm{~g}$ (RMV: $450 \mathrm{~g}$ and $375 \mathrm{~g}$ ), respectively. The external surface of both lungs was smooth and anthracotic. On sectioning, the parenchyma was reddish and firm. The histologic examination showed several tumoral thrombi (Figure 3), diffuse alveolar damage with hemorrhage, and foci of pneumonia with micro abscesses besides pleural thickening.

Mediastinal lymph nodes were enlarged, and the anthracotic pigment was replaced by a whitish firm infiltration, which was represented by neoplastic tissue (Figure 4). The bone marrow was hypercellular at the expense of all cell lineages, but no neoplastic invasion was found.

Additional findings comprised non-disrupted, calcified atherosclerotic plaques along the abdominal and thoracic aorta, basilar artery and left coronary artery; an old cerebellar infarction; and nodular prostatic hyperplasia.

Gross and microscopic examination of retroperitoneal lymph nodes, and remaining organs were unremarkable.

Respiratory insufficiency due to pulmonary tumoral emboli and pneumonia were considered to be the immediate cause of death. Right-sided cardiac metastases were blamed as the source of tumoral emboli.
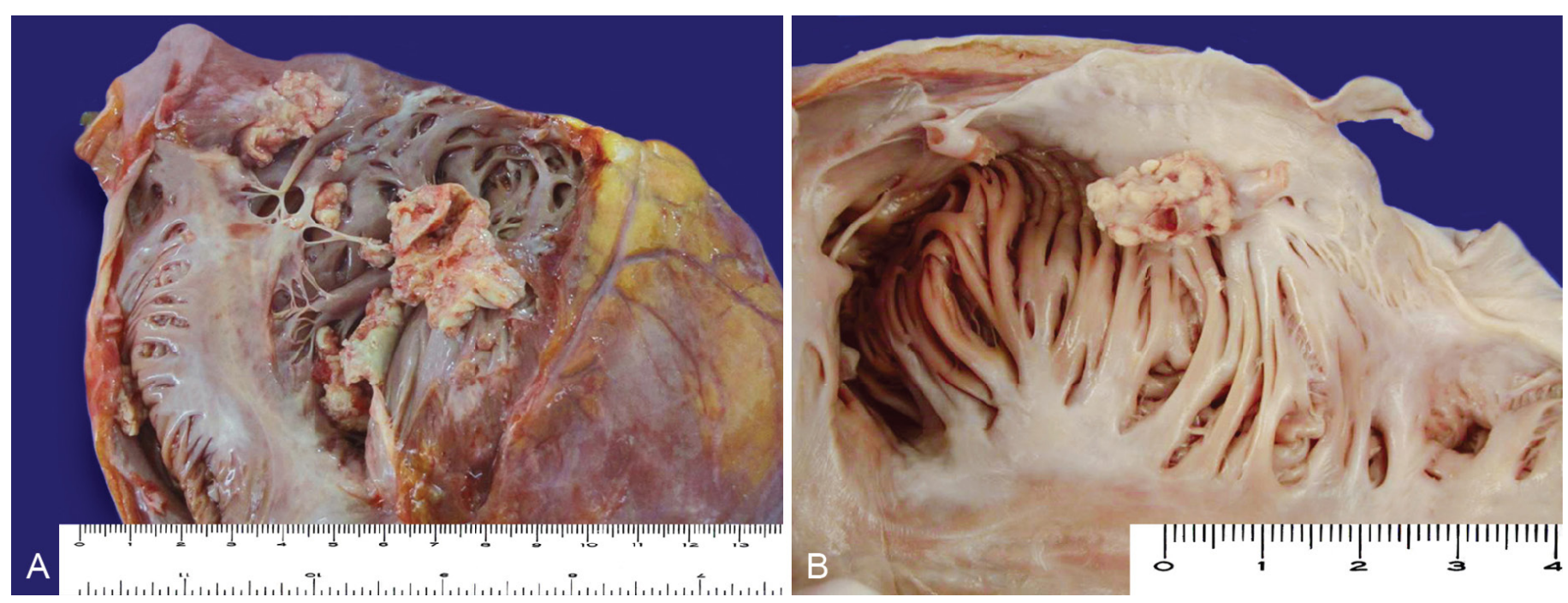

Figure 1 - Gross view of the right cardiac chambers. A - Right atrium and tricuspid valve; $\mathbf{B}$ - Inside view of the right atrium, note that the metastatic vegetation is growing attached to a sheet of fibrous tissue that covered the pacemaker lead. In both, note the cauliflower-shaped vegetation attached to the endocardium. 

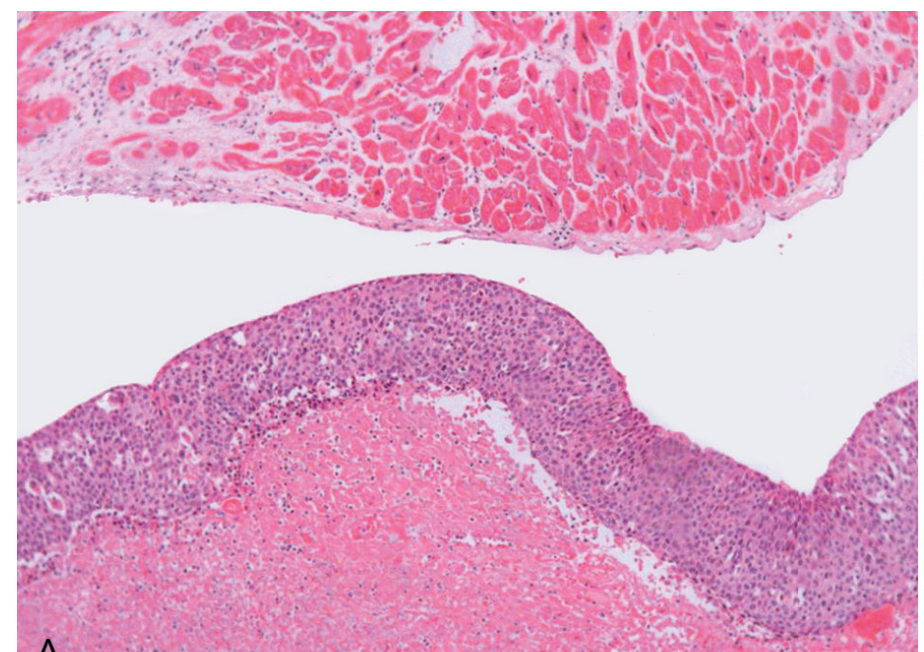

A

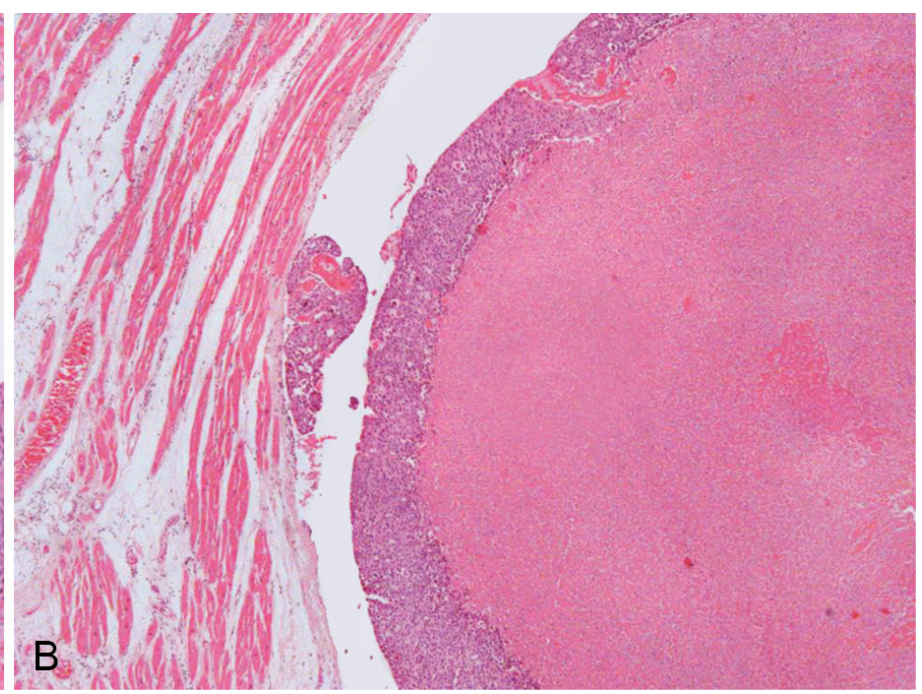

Figure 2 - A and B - Photomicrography of the endocardium, myocardium and tumoral mass. In B, note the proximity of the neoplasia and the endocardium (H\&E, 100X).

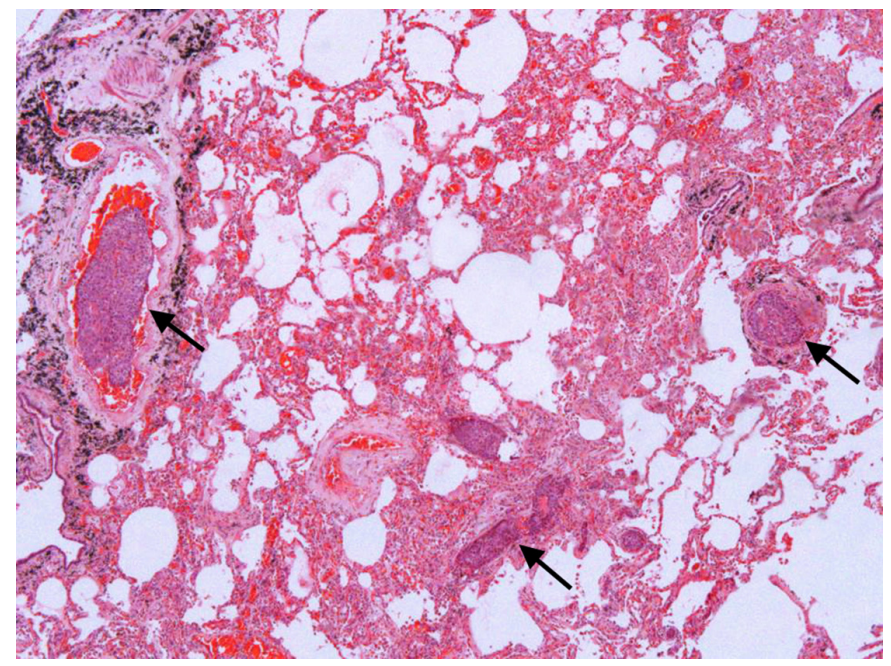

Figure 3 - Photomicrography of the lung showing tumoral thrombi (arrows) (H\&E, 100X).

\section{DISCUSSION}

Penile cancer is a rare entity in Europe and the USA where it accounts for $0.3-0.7 \%$ of all malignant tumors in men. The age standardized incidence is 0.3-1 per 100,000 men in European countries and the USA; whereas it is much higher in developing countries: 3 per 100,000 men in parts of India; 8.3 per 100,000 men in Brazil, and even higher in Uganda. The causes of this geographical variation is not well established, but decreased incidence of the disease is associated with better hygiene habits and routine perinatal circumcision. ${ }^{1,2}$ In 2012 in the USA, it was estimated that the occurrence of 1,570 cases and 310 deaths was due to penile cancer. ${ }^{3}$ In Brazil, from May 2006 to June 2007, 283 new cases of penile cancer were recorded mainly in the north-

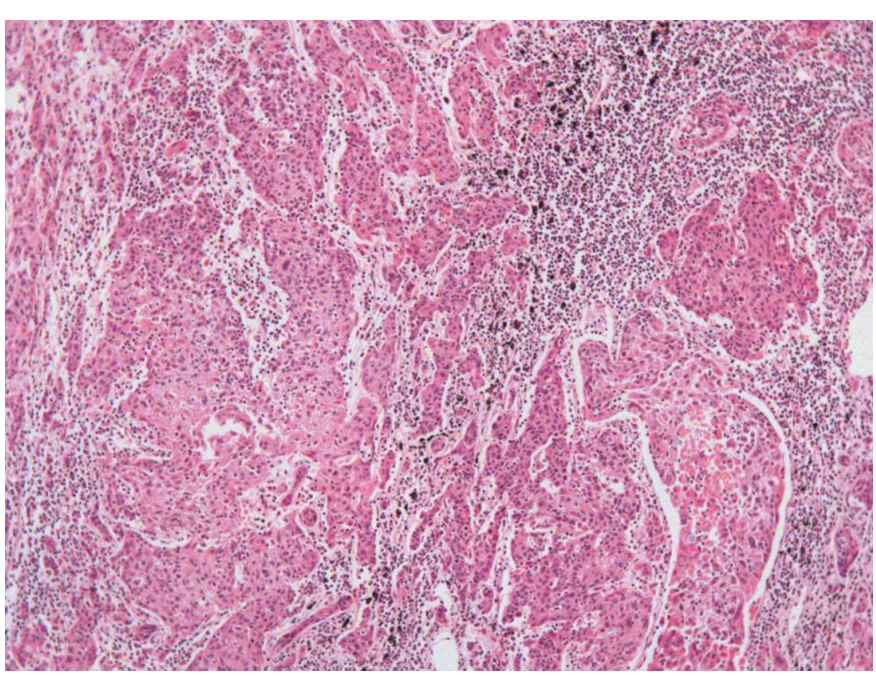

Figure 4 - Photomicrography of mediastinal lymph node showing effacement of the lymph node architecture by neoplastic invasion (H\&E, 200X).

northeast and southeast regions, which are regions with lower human development indexes. ${ }^{4}$

Among all the penile malignancies, squamous cell carcinoma is the most prevalent histological type,$^{5}$ with a relative frequency of approximately $95 \%$, followed by malignant melanoma, basal cell carcinoma, and others. ${ }^{1}$ The mean age at diagnosis is about 60 years; however, a prospective study in the UK suggested that $25 \%$ of men were younger than 50 years of age at diagnosis. ${ }^{6}$ In a Brazilian series containing 283 new cases of penile cancer, $7.41 \%$ of the patients were younger than 35 yearsold. ${ }^{3}$

Systematic review of publications from 1966 to 2000 found an association between the presence of foreskin and tumor development with 
the lack of local hygiene being highly favoured as a cause. ${ }^{7,8}$ Circumcision decreases the risk of penile cancer especially if it is performed during the neonatal period. ${ }^{9}$ Human papillomavirus (HPV), manly subtypes 16 and 18 , also play a role in the development of this tumor, since the association was demonstrated in up to $50 \%$ of penile cancers with this viral infection. ${ }^{10}$ Other reported risk factors include genital warts, multiple sexual partners, an early age of first intercourse, HIV infection, smoking (dose-depending effect). ${ }^{1}$

Penile squamous cell carcinoma usually spreads as follows: sentinel inguinal node(s), superficial inguinal lymph nodes, deep inguinal lymph nodes, pelvic lymph nodes, periaortic lymph nodes, mediastinal lymph nodes, regional dissemination to skin of groin, scrotum, perineum, direct invasion of prostate, and systemic dissemination to multiple sites like liver, lungs, and heart., 511 In a series involving 14 autopsies of patients with penile squamous cell carcinoma, the distant metastatic sites were concentrated in lymph nodes, liver, lungs, and the heart. The latter was characterized by myocardial involvement and clinically by arrhythmias. ${ }^{11}$ In contrast, Neuzillet et al. ${ }^{7}$ reported the metastatic sites of squamous carcinoma of the penis in a decreasing frequency as follows: lymph nodes, lungs, liver, bones, and exceptionally the brain, skin, kidneys, adrenals, and heart.

In general, the metastatic involvement of the heart did not provoke much interest, most likely because of its low incidence, as well as the paucity of clinical manifestations. The low incidence is probably due to a combination of factors, such as continuous myocardial contraction, metabolic particularity of the striated cardiac muscle, the rapid blood and lymph flow away from the heart, and restricted lymphatic connections. ${ }^{12,13}$ The studies conducted by Gassman et al., ${ }^{14}$ retrieved 4,124 autopsies of cancer cases during a 20-year period (from 1931 to 1951), in which the heart involvement totaled 217 cases, accounting for approximately $5 \%$ of all autopsies. Other autopsy studies show the incidence of metastatic cardiac disease, excluding leukemias, ranging from 0.5 to $19.1 \% .{ }^{14-16}$ This metastatic cardiac involvement is $20-40$ times more common than primary cardiac tumors. ${ }^{12,17}$ The cases in which the myocardium, endocardium, and epicardium were involved, represented 109 cases. The endocardium was predominantly involved in 16 cases $(7.3 \%)$, and only 5 cases $(0.048 \%$ of all autopsies) of those 16 were characterized by tumor thrombus in the heart chambers. ${ }^{14}$ This observation is in accordance with the Mukai et al. studies, ${ }^{18}$ which found endocardium involvement in $6 \%$ of the cardiac metastatic disease cases. In the studies by Gassman et al., ${ }^{14}$ the primary tumor site outside the thorax represented $43 \%$ of the cases and only three cases were related to penile carcinoma. Cardiac metastatic disease may developed by: contiguity (as bronchogenic and esophageal carcinomas), true embolic metastasis via coronary arteries and lymphatic spread due to the proximity of lymphatic trunks to the coronary vessels. However, many observers believe that hematogenous spread is the more likely route. ${ }^{14}$

Interestingly, $80 \%$ of this type of metastasis occurs in the right chambers of the heart, probably attributed to the filtering role of the pulmonary circulation and the slower right chambers' flow. ${ }^{19}$ Approximately $75 \%$ of primary tumors are represented by carcinomas, followed by hematological malignancies, melanomas, and sarcomas. ${ }^{16,18}$ In our patient's case, regional lymph nodes were surgically excised, and metastases were found in the heart, lungs, and thoracic lymph nodes. No metastases were found along the iliac and periaortic chains, which led us to accept an initial lymphatic spread, followed by a hematogenous neoplastic spread. As the cardiac tumoral mass was located in the right atrium, the massive presence of tumoral emboli in the lungs was expected and subsequently the pulmonary hilar nodes. We assumed that the pacemaker implantation was motivated by ischemic cardiopathy rather than myocardial neoplastic infiltration, since the latter was not detected in the thorough histologic examination of the heart. As considered by Byun et al. ${ }^{20}$, metastatic pulmonary emboli might decrease the right cardiac flow, rendering the right chambers more prone to inracavitary seeding. Moreover, in this case, we speculate if the pacemaker may have contributed, to some extent, to facilitate the tumor seeding, like in the case reported by Liao et al. ${ }^{21}$, where a primary cardiac sarcoma spread along the pacing leads, as the sole metastatic site.

To the best of our knowledge, no other report of intracardiac metastasis of penile squamous cell carcinoma associated with the presence of a pacemaker's electrodes has been found. It remains doubtful whether the presence of these electrodes played any role in this metastatic seeding process.

A PubMed search for the keywords metastasis, penis, carcinoma, and heart, revealed only three references concerning cases of metastasis 
of penile squamous cell carcinoma to the heart. One of the reports was Russian ${ }^{22}$ and the other was Polish. ${ }^{23}$ In both cases, the diagnoses were made during autopsy. The third case showed a massive metastatic neoplastic infiltration of the heart, at the level of the interatrial and interventricular septa, the free wall of both ventricles, the perivalvular mitral area, the pericardium, and the ventricular apex. In this case, the diagnosis was made before the patient's death and was also confirmed during autopsy. ${ }^{24}$ The same search on Science Direct resulted in a single article reviewing the atypical sites of metastatic penile cancer. In this article, a case of an AIDS patient with multi visceral metastases of squamous cell carcinoma of the penis was reported. ${ }^{25}$

\section{CONCLUSION}

The present case report calls attention to the tumoral involvement of locoregional lymph nodes and heart. The lung involvement was secondary to neoplastic embolization. Previous cardiomyopathy and the presence of the pacemaker electrodes were possible risk factors for intracardiac tumoral seeding. Even though this report showed the concomitance of the cited factors, further research is required to investigate whether they represent a coincidence or a statistically significant phenomenon. To the best of our knowledge, this is the first Brazilian report on penile squamous cell carcinoma of the penis with intracardiac metastases.

\section{REFERENCES}

1. Arya M, Kalsi J, Kelly J, Muneer A. Malignant and premalignant lesions of the penis. BMJ. 2013;346:f1149. http://dx.doi. org/10.1136/bmj.f1149

2. European Association of Urology. Online guidelines [Internet]. [place unknown]: European Association of Urology; 2012. Available from: www.uroweb.org/guidelines/online-guidelines/

3. American Cancer Society. What are key statistics about penile cancer? [place unknown]; c2013 [cited 2013 May 29]. Available from: http://www.cancer.org/cancer/penilecancer/ detailedguide/penile-cancer-key-statistics

4. Favorito LA, Nardi AC, Ronalsa M, Zequi SC, Sampaio FJ, Glina S. Epidemiologic study on penile cancer in Brazil. Int Braz J Urol. 2008; 34:587-91. PMid:18986562. http://dx.doi. org/10.1590/S1677-55382008000500007
5. Ebele JN, Sauter G, Epstein JI, Sesterhenn IA. Pathology and genetics of tumours of the urinary system and male genital organs. Lyon: IARC Press; 2004.

6. Hegarthy PK, Kayes O, Freeman A, Christopher N, Ralph DJ, Minhas S. A prospective study of 100 cases of penile cancer managed according to European Association of Urology guidelines. BJU Int. 2006;98:526-31. PMid:16925747. http:// dx.doi.org/10.1111/j.1464-410X.2006.06296.x

7. Neuzillet Y, Méjean A, Lebret T. [Rare locations of metastases from penile cancer]. Prog Urol. 2008;18(Suppl 7):396-8. French. http://dx.doi.org/10.1016/S1166-7087(08)74573-1

8. Dillner J, von Krogh G, Horenblas S, Meijer CJ. Etiology of squamous cell carcinoma of the penis. Scand $J$ Urol Nephrol Suppl. 2000;205:189-93. http://dx.doi. org/10.1080/00365590050509913

9. Maden C, Sherman KJ, Beckmann AM, et al. History of circumcision, medical conditions, and sexual activity and risk of penile cancer. J Natl Cancer Inst. 1993;85:19-24. http://dx.doi.org/10.1093/jnci/85.1.19

10. Miralles-Guri C, Bruni L, Cubilla AL, Castellsagué X, Bosch FX, de Sanjosé S. Human papillomavirus prevalence and type distribution in penile carcinoma. J Clin Pathol. 2009;62:870-8. PMid:19706632. http://dx.doi.org/10.1136/jcp.2008.063149

11. Chaux A, Reuter V, Lezcano C, Velazquez E, Codas R, Cubilla $\mathrm{AL}$. Autopsy findings in 14 patients with penile squamous cell carcinoma. Int J Surg Pathol. 2011 Apr;19:164-9. http:// dx.doi.org/10.1177/1066896909333781

12. Borsaru AD, Lau KK, Solin P. Cardiac metastasis: a cause of recurrent pulmonary emboli. Br J Radiol. 2007;80:e50-3. PMid:17495056. http://dx.doi.org/10.1259/bjr/94870835

13. Prichard RW. Tumors of the heart: review of the subject and report on 150 cases. Arch Pathol. 1951;51:98-128.

14. Gassman HS, Meadows R Jr, Baker LA. Metastatic tumors of the heart. Am J Med. 1955;19:357-65. http://dx.doi. org/10.1016/0002-9343(55)90124-8

15. Lam KY, Dickens P, Chan ACL. Tumors of the heart: a 20 year experience with a review of 12485 consecutive autopsies. Arch Pathol Lab Med.1993;117:1027-31. PMid:8215825.

16. Shapiro LM. Cardiac tumours: diagnosis and management. Heart. 2001;85:218-22. http://dx.doi.org/10.1136/ heart.85.2.218

17. Butany J, Leong SW, Carmichael K, Komeda M. A 30-year analysis of cardiac neoplasms at autopsy. Can J Cardiol. 2005;21:675-80. PMid:16003450.

18. Mukai K, Shinkai T, Tominaga K, Shimasato $Y$. The incidence of secondary tumors of the heart and pericardium: a 10-year study. Jpn J Clin Oncol. 1988;18:195-201. PMid:3411785. 
19. Sutsch G, Jenni R, Von Segesser L, Schneider J. Heart tumours: incidence, distribution, diagnosis. Exemplified by 20,305 echocardiographies. Schweiz Med Wochenschr. 1991;121:621-9. PMid:2047823.

20. Byun SW, Park ST, Ki EY, et al. Intracardiac metastasis from known cervical cancer: a case report and literature review. World J Surg Oncol. 2013;11:107. PMid:23702302 PMCid:PMC3667008. http://dx.doi.org/10.1186/1477-781911-107

21. Liao JN, Chen IM, Yang AH, Yu WC. A primary cardiac sarcoma spreading along the pacing leads of a permanent pacemaker. J Am Coll Cardiol. 2012;59:1487. PMid:22497829. http://dx.doi.org/10.1016/j.jacc.2011.07.062

\section{Conflict of interest: None.}

Submitted on: $3^{\text {rd }}$ June 2013

Accept on: $3^{\text {rd }}$ November 2013

Correspondence: Departamento de Patologia Hospital das Clínicas da Faculdade de Medicina da USP Av. Enéas Carvalho de Aguiar, 155 - São Paulo/SP - Brazil CEP: 05403-000 - Phone: +55 (11) 2661-6281

E-mail: satie.tomikawa@gmail.com
22. Magomedov MK. [Metastasis of squamous cell carcinoma of the penis into the heart]. Arkh Patol. 1998;60:59-61. Russian. PMid:9612515.

23. Swierz J, Poznański J, Stawarz B. [Metastasis of penile cancer to the heart in a 20-year-old patient]. Wiad Lek. 1992;45:314-6. Polish. PMid:1462597.

24. Portero JN, Pardo FL, Pérez RC. Massive intracardiac metastases secondary to squamous cell carcinoma located at the level of the penis. Int J Cardiol. 2008;127:e96-7. PMid:17707529. http://dx.doi.org/10.1016/j.jjcard.2007.04.092

25. Théodore C, Androulakis N, Spatz A, Goujard C, Blanchet P, Wibault P. An explosive course of squamous cell penile cancer in an AIDS patient. Ann Oncol. 2002:475-9. PMid:11996481. http://dx.doi.org/10.1093/annonc/mdf024 